\title{
Evaluation of the Strength Characteristics of Cunninghamia lanceolata Timber Using Continuous Mechanical Stress Rating Equipment
}

\begin{abstract}
Chiaju Lee, ${ }^{\mathrm{a}, \mathrm{c}}$ Chihhsein Lin, ${ }^{\mathrm{b}}$ Minjay Chung, ${ }^{\mathrm{a}, *}$ and Mingjer Tsai ${ }^{\mathrm{c}, * *}$
Before timber is used for engineering and structural purposes, it is necessary to grade the strength of the timber. In order to obtain the static modulus of elasticity value of timber quickly and accurately, this study used ultrasonic waves and continuous mechanical stress rating equipment and two non-destructive test methods to analyze the correlation between the non-destructive test measured value and the static modulus of elasticity value. It also evaluated the influence of the feeding orientation of the boards, the forward and reverse feed directions, feeding speed, and break area ratio. The analysis results indicated that the modulus of elasticity value determined through continuous mechanical stress rating equipment had the highest correlation with the static modulus of elasticity value. Moreover, according to the results, the feeding orientation of the boards, the forward and reverse feed directions, and the feeding speed did not influence the prediction of the continuous mechanical stress rating equipment modulus of elasticity value. Meanwhile, to ensure the accuracy and uniformity of the continuous mechanical stress rating equipment modulus of elasticity detection value, it is necessary to avoid an excessively high break area ratio in Cunninghamia lanceolata timber during the preparation process.
\end{abstract}

DOI: 10.15376/biores.17.1.1411-1426

Keywords: Cunninghamia lanceolata; Nondestructive testing; Machine stress rated grading; Continuous mechanical stress rating equipment

Contact information: a: Experimental Forest, National Taiwan University, No. 12, Section 1, Chien-Shan Road, Chu-Shan, Nantou Hsien 55750 Taiwan; b: Department of Forestry, National Chung Hsing University. No. 145 Xingda Rd, South Dist, Taichung City 40227 Taiwan; c: School of Forestry and Resource Conservation, National Taiwan University, Taipei 10617 Taiwan;

*Co-corresponding author:r90625001@ntu.edu.tw; **Co-corresponding author: tmj@ntu.edu.tw

\section{INTRODUCTION}

In recent years, forest plantation tending and the reforestation of slope land have shown fruitful results. Proper thinning operations help stand density management and tree growth as well as enhance stumpage values (Pirard et al. 2016; McEwan et al. 2020). It should be noted that plantation forests in Taiwan are more suited to growth at mid-high altitude zones, where coniferous species, e.g., Chinese fir (Cunninghamia lanceolata), Japanese cedar (Cryptomeria japonica), and Taiwan fir (Taiwania cryptomerioides), are particularly abundant. Thus, using these thinning timbers for architectural and structural applications could increase the value of thinned wood and promote the effective use of forest resources (Chen et al. 2005; Cao et al. 2019). However, domestic thinned wood is mostly composed of small-medium diameter timbers, with a high proportion of juvenile wood and knots, which often causes the quality and strength of the timber to decrease. 
Therefore, before thinned timbers are used as structural materials, they must be subjected to strength analysis in order to meet the requirements of structural timbers.

Additionally, Firmanti et al. (2005) and França et al. (2021) stated that the strength and stiffness of wood are primarily determined by specific gravity, fiber and tissue characteristics, and defects or flaws of wood, e.g., density, knots (number, size, and position of knots on the board), slope of the grain, and interlocked grain. Moreover, there can be great differences between different tree species or even among the same tree species. Therefore, in order to ensure the safety of wood structure materials, nondestructive testing (NDT) methods, e.g., visual grading, and mechanical grading or a combination of the two grading methods are used to detect the internal flaws and external shortcomings of the wood.

Some studies have analyzed the structure compositions and properties of materials based on the above methods and used their findings as the basis for quality identification (Wang et al. 2008; Brashaw et al. 2009; Kovryga et al. 2020). Based on simplification and cost considerations, timbers with similar mechanical properties are placed in the same category of stress level (Ross 2015). Moreover, the strength properties of timber are mostly linearly proportional to the modulus of elasticity (MOE). Thus, NDT is used for determining the MOE value of timber as the basis for estimating its strength properties (Firmanti et al. 2005; Ross 2015). Generally, in addition to the measurement and classification of the actual MOE value of wood materials using a universal strength testing machine, ultrasonic wave and tap-tone sound measuring methods are also used to analyze the dynamic moduli of elasticity (DMOE) of wood materials (Wang et al. 2008; Kovryga et al. 2019; 2020).

Mechanical stress rating (MSR) is currently the most important method for grading the strength of wood materials. However, although a universal strength testing machine can measure the static MOE value of timbers, due to its slow operation speed, this kind of machine is only suitable for use in laboratory analysis of the various strength properties of materials. The ultrasonic wave and tap-tone sound measuring methods can readily detect the DMOE value of timber, and through correlation analysis with the actual MOE, the stress level between each material can be indirectly determined. However, there are big differences between the DMOE values of various tree species and the static MOE (Ross 2015).

In view of this, this study uses a three-point load method to measure the actual MOE value of timber and is equipped with a mechanical stress grading device with a roller design that can accommodate the speed of production line load cells and the continuous mechanical stress rating equipment (CMSR) of rapid analysis computer technology. The test content includes analysis of the MOE ${ }_{C M S R}$ and static $\mathrm{MOE}_{\text {static }}$ value, the ultrasonic measurement of the DMOE correlation, and evaluation of the CMSR analysis methods, e.g., feeding direction and board surface characteristics. Furthermore, the proposed method evaluates the analysis method of the CMSR, e.g., the feeding direction and board surface characteristics, and the influence of whether the bark side is up or down on the bending properties. This includes bending tests that are static and continuous, analysis methods related to the ultrasonic measurement of the DMOE, e.g., feed direction and board surface characteristics, and a comparison of the influence of the bark facing upwards or downwards against the bending properties. 


\section{EXPERIMENTAL}

\section{Materials}

The 25- to 30-year-old China fir (Cunninghamia lanceolata) samples were collected from the Neimaopu tract in the Experimental Forest of the National Taiwan University in Nan-Tou County, Taiwan in October of 2018. All the China fir trees were cut into $3.6 \mathrm{~m} \times 8.9 \mathrm{~cm} \times 3.5 \mathrm{~cm}$ (length $\times$ width $\times$ thickness) sized samples; 40 specimens $(\mathrm{n}=40)$ were dried to less than $15 \%$ by kiln drying and were tested for each condition.

\section{Methods}

Relationship between the various bending elastic modulus analysis methods

The following relationships were analyzed in this study: (1) the relationship between the modulus of elasticity (MOE $\left.\mathrm{M}_{\text {static }}\right)$ and the ultrasonic-wave velocity $\left(V_{\mathrm{u}}\right)$ speed of transmission, as well as the dynamic modulus of elasticity $\left(\mathrm{DMOE}_{\mathrm{u}}\right)$; (2) the relationship between the MOE of the continuous mechanical stress rating machine (MOE CMSR $_{\text {) }}$ and the $V_{\mathrm{u}}$ speed of transmission, as well as the $\mathrm{DMOE}_{\mathrm{u}}$; and (3) the relationship between the $\mathrm{MOE}_{\text {static }}$ and the MOE $\mathrm{CMSR}$.

Feeding rate of the continuous mechanical stress rating equipment (CMSR)

Three different speeds were analyzed to determine the differences between feeding speeds of the continuous mechanical stress rating machine (CMSR): $40 \mathrm{~m} / \mathrm{min}(22.95 \mathrm{~Hz})$, $60 \mathrm{~m} / \mathrm{min}(34.44 \mathrm{~Hz})$, and $80 \mathrm{~m} / \mathrm{min}(45.90 \mathrm{~Hz})$.

\section{Feeding plate surface direction and feeding method}

The CMSR had a roller-shaped three-point bending design. The material surface of the feed was the tensile side of the bending test. Therefore, the bark side of the specimen was placed bark up and down (as shown in Fig. 1) and the difference between the forward and reverse feed directions was evaluated.

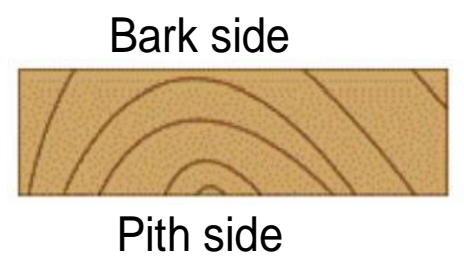

Fig. 1. Schematic diagram of the bark side and pith side of the specimen

\section{Characteristics of different break areas}

The term "break area (BA)" means drilling failure area. It is mainly to simulate the cross-sectional area loss in the vertical wood direction caused by knots or wormholes. It was reduced by $13 \%, 27 \%$, and $40 \%$, and holes were made in the laminae artificially. The recorded data point of the maximum value of the MOE CMSR. As shown in Table 1, since the CMSR uses roller mechanisms for feeding, reducing the feeding speed can lead to a higher data point frequency, which can provide a more accurate distribution of data. 
Table 1. Drilling Position of the Laminae and the Data Volume of the Mechanical Stress Rating (MSR)

\begin{tabular}{|c|c|c|c|c|}
\hline \multirow{2}{*}{ Lumber Position (mm) } & \multirow{2}{*}{ CMSR Data Account (No.) } & \multicolumn{3}{|c|}{ MOE $_{C M S R}$ Ratio Decrease (\%) } \\
\hline & & BA-13\% & BA-27\% & BA- $-40 \%$ \\
\hline 1430 & 154 & 2.82 & 5.63 & 8.45 \\
\hline 1800 & 221 & 4.73 & 6.77 & 8.89 \\
\hline 2170 & 291 & 2.70 & 6.76 & 9.46 \\
\hline
\end{tabular}

\section{Static bending test}

The centralized load tests of this investigation were conducted using a universal strength testing machine (AG-IC $250 \mathrm{kN}$, Shimadzu, Kyoto, Japan). The upper limit load and lower limit load, along with the corresponding deflection difference within the proportional limit, were recorded. Bending strength analysis was carried out according to CNS standard 2215 (2017), which involved the following procedures. The constant temperature and humidity chamber should be adjusted to a temperature of $20{ }^{\circ} \mathrm{C}$ at a relative humidity of $65 \%$ for two weeks. The length of each dimension was measured, and the test material thickness was set as 20 times the load of a $600 \mathrm{~mm}$ unit test sample, with a load speed of $10 \mathrm{~mm} / \mathrm{min}$. The modulus of elasticity $\left(\mathrm{MOE}_{\text {static }}\right)$ was calculated according to the Eq. 1,

$$
M O E_{\text {static }}(M P a)=\frac{\Delta P L^{3}}{4 \delta b h^{3}}
$$

where $L$ is the span (mm), $b$ is the width (mm), $h$ is the depth (mm), $\Delta P$ is the difference between the upper limit load and the lower limit load within the proportional limit $(\mathrm{N})$, and $\delta$ is the bending deformation of the center of the span relative to $\Delta P$.

In addition, the mechanical grades of the laminae were distinguished according to the cross laminated timber outlined in CNS standard 11031 (2014) and the Japanese Agricultural Standard standards (JAS) 1152 (2007) (as shown in Table 2).

Table 2. CNS Standard 11031 (2014) Mechanical Stress Rating (MSR) Grading Level of the Structural Glulam for Laminae

\begin{tabular}{|c|c|c|}
\hline CNS Grade & MOE (GPa) & \multirow{3}{*}{ JAS CLT Grade } \\
\hline L200 & 20.0 & \\
\hline L180 & 18.0 & \\
\hline L160 & 16.0 & \\
\hline L140 & 14.0 & \multirow{2}{*}{ M90 } \\
\hline L125 & 12.5 & \multirow{2}{*}{ M60 } \\
\hline L110 & 11.0 & \\
\hline L100 & 10.0 & \\
\hline L90 & 9.0 & \multirow{2}{*}{ M30 } \\
\hline L80 & 8.0 & \\
\hline L70 & 7.0 & \\
\hline L60 & 6.0 & \\
\hline L50 & 5.0 & \\
\hline L40 & 4.0 & \\
\hline L30 & 3.0 & \\
\hline
\end{tabular}




\section{Continuous mechanical stress rating}

This experiment utilized an SSR-7001 continuous mechanical stress rating machine (CMSR) from Advanced Technology Associates Co. (Westlake, OH) (as shown in Fig. 2). The machine is divided into three sets of rollers, at the front, central, and end, starting from the feeding direction. The machines spans a total of $1200 \mathrm{~mm}$ from the front to end sections. It has a load detection mechanism for recording the upward MOE. Table 3 shows the CMSR efficiency. The feeding speed is between 40 and $80 \mathrm{~m} / \mathrm{min}$ over spans between 1200 and $1207 \mathrm{~mm}$, with a maximum load of $500 \mathrm{kgF}$. The system uses laser detection to record the load resistance data once the sample has passed the mid-section rollers.

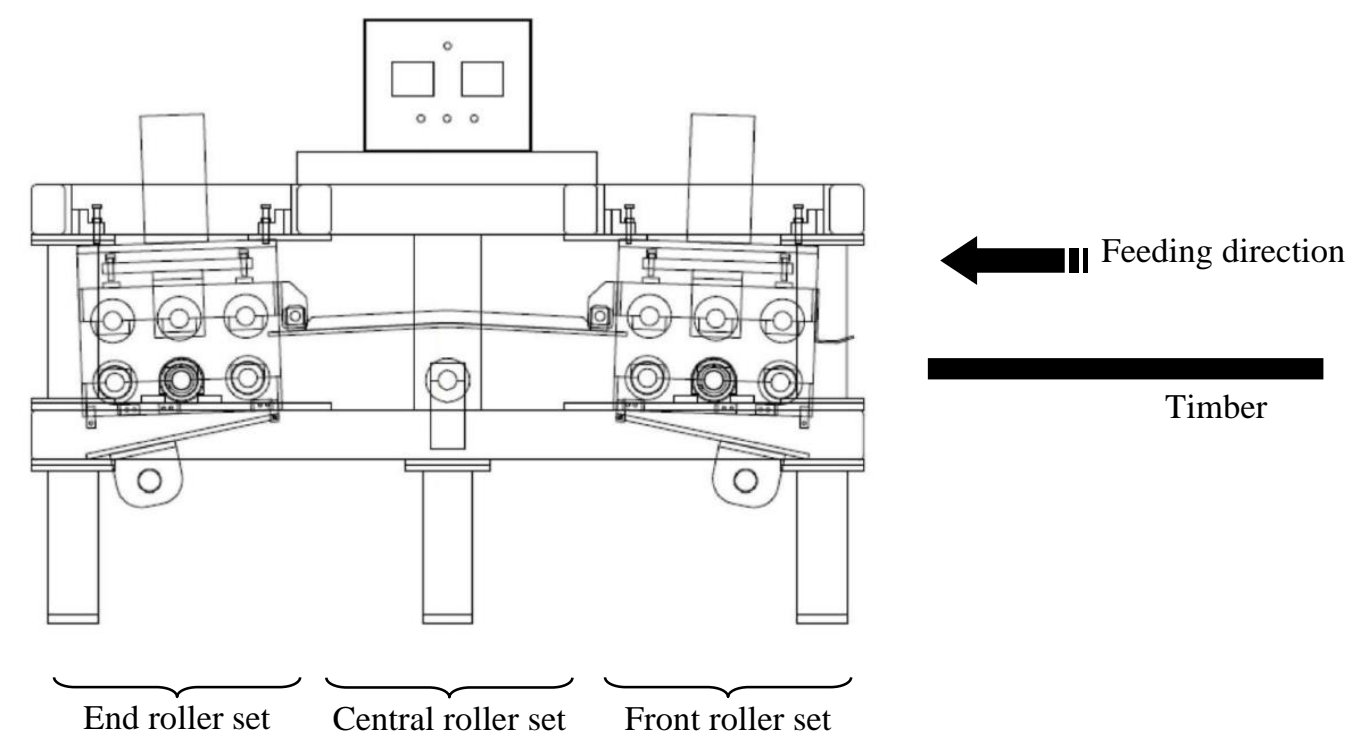

Fig. 2. Continuous mechanical stress rating equipment

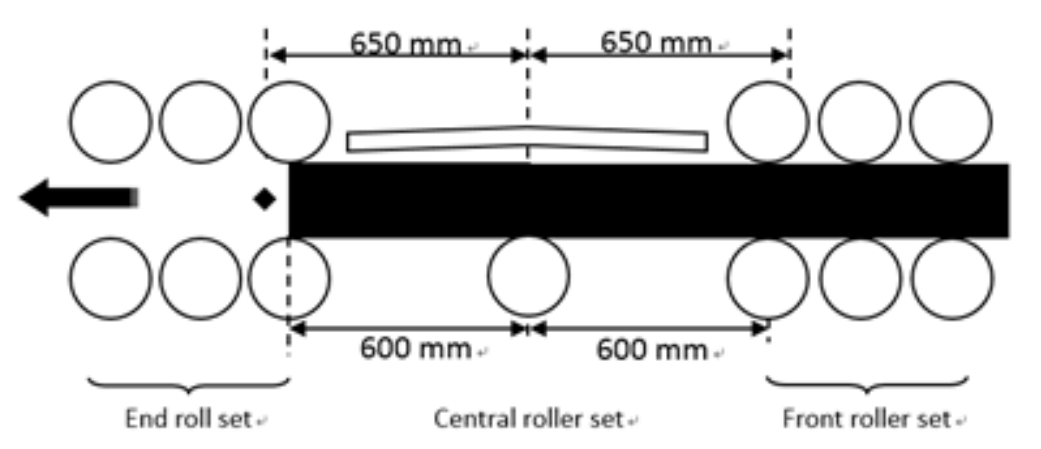

Fig. 3. Measuring range of the continuous mechanical stress grading equipment

Figure 3 shows the relative location between the specimens and the test machine with the laser detector at $1300 \mathrm{~mm}$, which covers $1250 \mathrm{~mm}$ of the specimens. The system begins to collate the MOECMSR values and calculate its mean, maximum, and minimum values according to the CNS standard 11031 (2014) to establish the grading system via spray-painting a particular color. The color standards were outlined according to the guidelines of JAS 1152 (2007) for laminated timber. The four colors, i.e., M30, M60, M90, and M120, are distinguished by the MOE value. 
Table 3. Efficacy of the Continuous Mechanical Stress Rating Equipment (CMSR)

\begin{tabular}{|c|c|c|}
\hline \multicolumn{2}{|c|}{ Project } & Performance \\
\hline \multirow{4}{*}{ Machine } & Feeding speed & 40 to $80(\mathrm{~m} / \mathrm{min})$ \\
\cline { 2 - 3 } & Pivot spacing & 1200 to $1207(\mathrm{~mm})$ \\
\cline { 2 - 3 } & Load range & 0.0 to $500.0(\mathrm{kgF})$ \\
\cline { 2 - 3 } & Accuracy & $0.1(\mathrm{kgF})$ \\
\hline \multirow{3}{*}{ Timber } & Length & 2500 to $6000(\mathrm{~mm})$ \\
\cline { 2 - 3 } & Width & 80 to $250(\mathrm{~mm})$ \\
\cline { 2 - 3 } & Thickness & 18 to $45(\mathrm{~mm})$ \\
\hline
\end{tabular}

Ultrasonic wave settings

Non-destructive evaluation techniques were conducted to evaluate the ultrasonicwave velocity $\left(V_{u}\right)$, as shown in Eq. 2 ,

$$
V_{u}=\frac{L}{t}
$$

where $V_{u}$ is the ultrasonic transmission speed (m/s), $L$ is the length of the test material (m), and $t$ is the transmission time (s), and the dynamic modulus of elasticity (DMOE $\mathrm{u}$ ), as shown in Eq. 3,

$$
D M O E_{u}=\rho V_{u}^{2}
$$

where $\rho$ is the mass density $\left(\mathrm{kg} / \mathrm{m}^{3}\right)$, by using a portable ultrasonic non-destructive testing device (Sylvatest Duo, Saint Sulpice, Switzerland) at a frequency of $22 \mathrm{kHz}$. The specimens were placed between the transmitting and receiving transducers $(n=40)$, and the travel times of the ultrasonic waves (transmission time) were recorded.

\section{Statistical analysis}

This study used SPSS analysis software (Statistics v20, IBM, Armonk, NY) to diagnose the analysis of variance (ANOVA) using Scheffe's Method and Tukey's Test. The difference between each set of data revealed a 95\% confidence interval (CI). The regression analysis of each test was carried out using Microsoft Office 2007 Excel to test the significance of each regression.

\section{RESULTS AND DISCUSSION}

Relationship between Various Measurements of Modulus of Elasticity (MOE) Relationship between the modulus of elasticity (MOE $\left.E_{\text {static }}\right)$, ultrasonic velocity $\left(V_{u}\right)$, and dynamic modulus of elasticity $\left(D M O E_{u}\right)$

Figures 4 and 5 present the linear regression analysis between the MOEstatic and $V u$ and the MOEstatic and $\mathrm{DMOE}_{\mathrm{u}}$, respectively. The linear regression graph shows that the $\mathrm{MOE}_{\text {static }}$ increased as the $V_{\mathrm{u}}$ and DMOEu increased. The results of Figs. 4 and 5 also indicate that the slopes of the two linear regression equations were all positive and both the $V_{\mathrm{u}}$ and $\mathrm{DMOE}_{\mathrm{u}}$ were positively correlated with the $\mathrm{MOE}_{\text {static. }}$. From the coefficient of determination $\left(\mathrm{R}^{2}\right)$ results, it can be seen that the two linear regression equations were able to effectively explain the correlation between the $\mathrm{MOE}_{\text {static }}$ and the two independent variables, i.e., $V_{\mathrm{u}}$, and $\mathrm{DMOE}_{\mathrm{u}}$. 


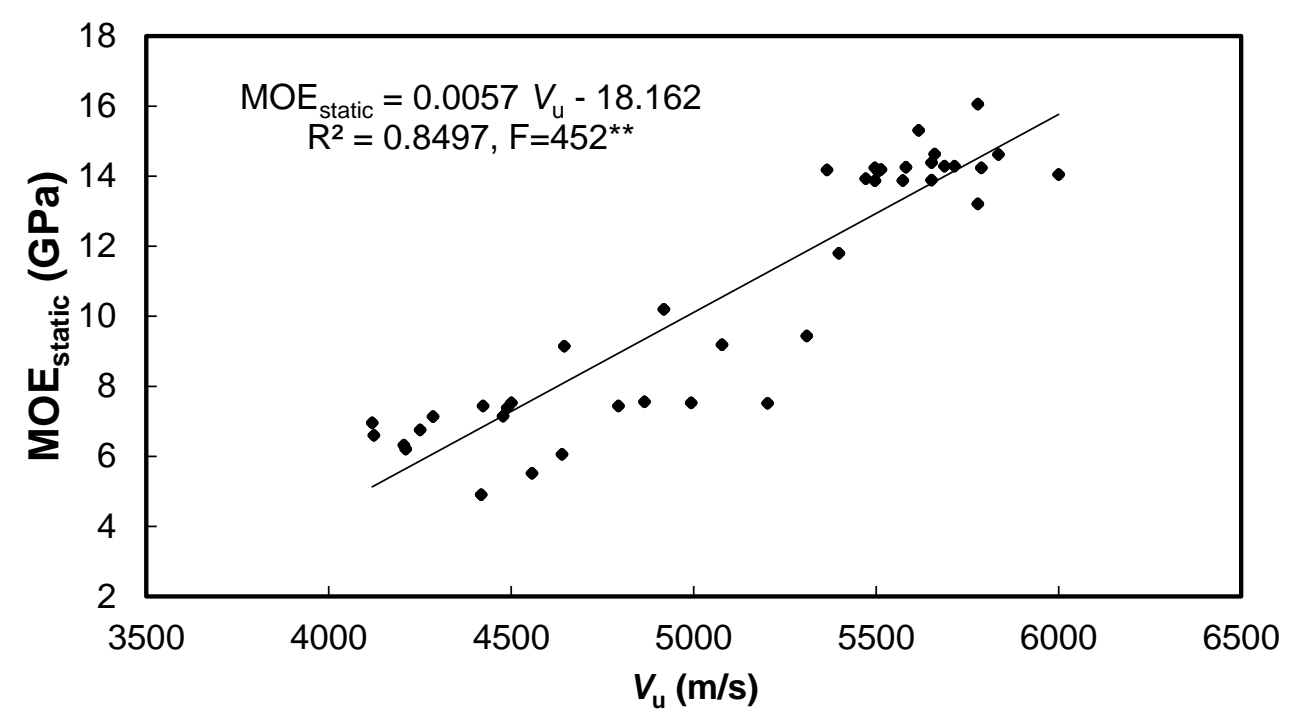

Fig. 4. Correlation between the $\mathrm{MOE}_{\text {static }}$ and the ultrasonic velocity $\left(V_{\mathrm{u}}\right)$ of $C$. lanceolata

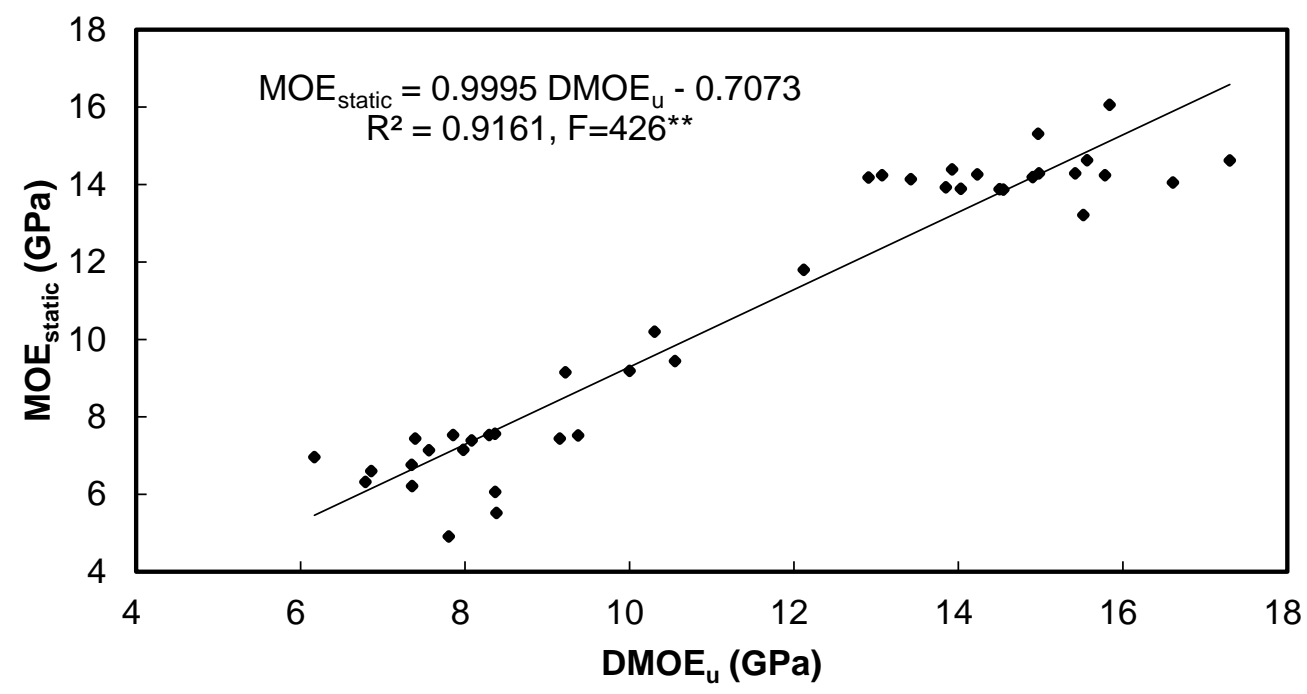

Fig. 5. Correlation between the $\mathrm{MOE}_{\text {static }}$ and the $\mathrm{DMOE}_{\mathrm{u}}$ of $C$. lanceolata

The p-values of the two sets of regression formulas were all less than 0.01 , which indicated that this regression formula was significant and had predictive potential. However, from the comparison results of the coefficient of determination values of the regression formula, it can be found that the value of the $\mathrm{DMOE}_{\mathrm{u}}(0.9161)$ was higher than the $\mathrm{R}^{2} V_{\mathrm{u}}(0.8497)$, which indicated that compared to the $\mathrm{MOE}_{\text {static }}$, using the $\mathrm{DMOE}_{\mathrm{u}}$ for testing is more apt. Ilic (2001) also used ultrasonic detection to predict the MOE of Eucalyptus delegatensis. The results indicated that both the vertical $\mathrm{DMOE}_{\mathrm{u}}$ and $V_{\mathrm{u}}$ held a significant positive correlation with the MOE value. The $\mathrm{R}^{2}$ value of the vertical $\mathrm{DMOE}_{\mathrm{u}}$ and MOE was 0.95, while the $\mathrm{R}^{2}$ value of the $V_{\mathrm{u}}$ and MOE was 0.78. Besides, Wang et al. (2008) indicated that the DMOE was slightly higher than MOE value, and there were good relationships between the DMOE and MOE of the four softwood lumber. Chung and Wang (2018) and Lee et al. (2021) also revealed that when using ultrasound to measure oriented Phyllostachys makinoi and $P$. pubescens scrimber boards, their $V_{\mathrm{u}}$ and DMOEu 
had a high correlation with the MOE value. As can be known from the above related studies, these results may have been influenced by the tree species, factors such as preparation conditions, or the testing environment, which showed a different pattern compared to the results of this study. However, these experiments showed that the $\mathrm{DMOE}_{\mathrm{u}}$ can be used to accurately predict the MOE value.

Relationship between the modulus of elasticity of the continuous mechanical stress rating machine (MOE $\left.E_{C M S R}\right)$, ultrasonic velocity $\left(V_{u}\right)$, and dynamic modulus of elasticity $\left(D M O E_{u}\right)$

Figures 6 and 7 show the relationships between the average values of the MOECMSR and the $V_{\mathrm{u}}$ with $\mathrm{DMOE}_{\mathrm{u}}$, respectively.

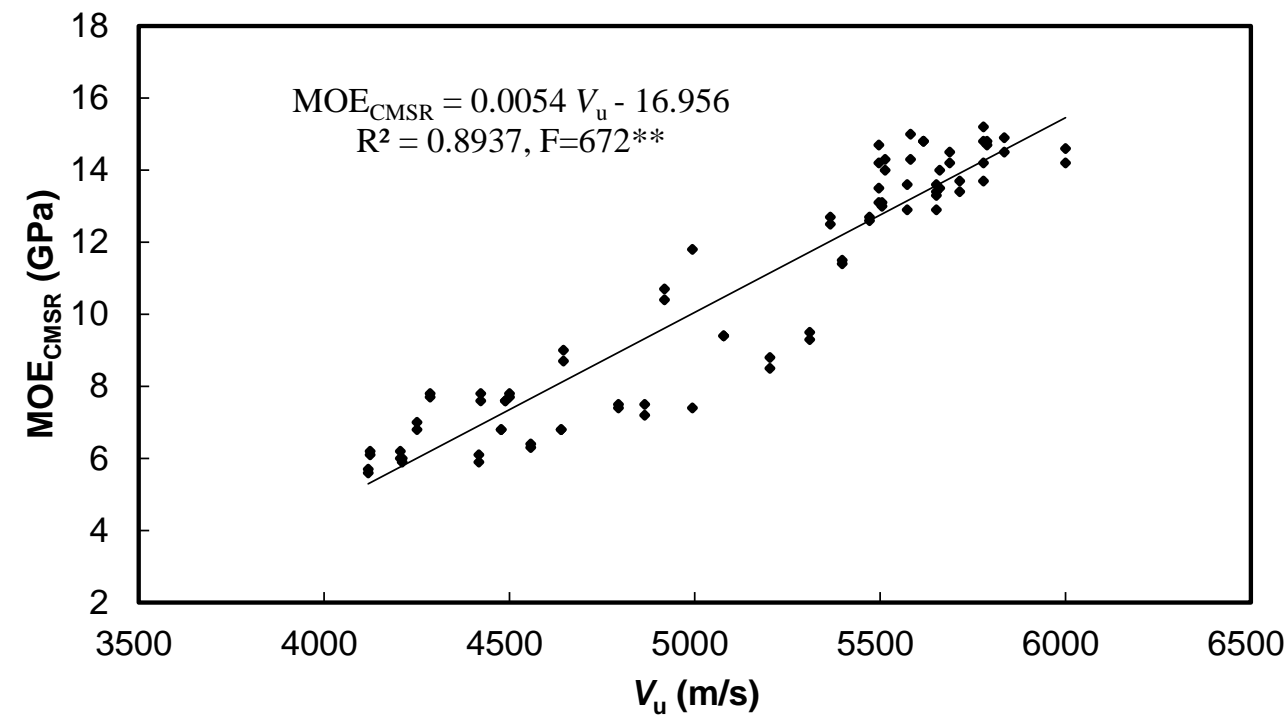

Fig. 6. Correlation between the $V_{\mathrm{u}}$ and $\mathrm{MOE}_{\mathrm{CmSR}}$ of $C$. lanceolata

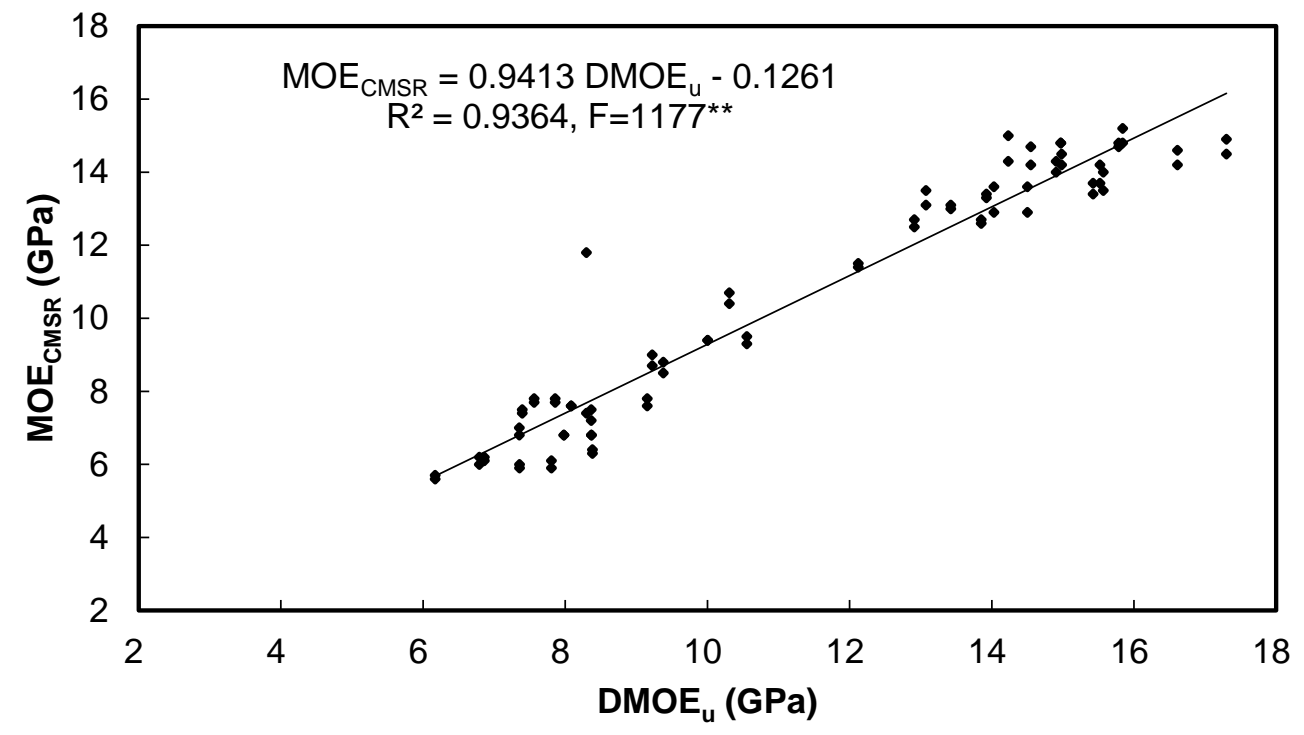

Fig. 7. Correlation between the $\mathrm{DMOE}_{\mathrm{u}}$ and $\mathrm{MOE}_{\mathrm{CMSR}}$ of $C$. lanceolata 
The slopes of the two sets of linear regression equations were all positive, which indicated that the $\mathrm{DMOE}_{\mathrm{u}}$ and $V_{\mathrm{u}}$ were positively correlated with the MOECMSR. The pvalue being less than 0.01 indicated that the two sets of regression held evident significance with each other; this further indicated that the $V_{\mathrm{u}}$ and $\mathrm{DMOE}_{\mathrm{u}}$ can be used to further predict the MOE $E_{C M S R}$ value with high reliability. Comparing the $\mathrm{R}^{2}$ values indicated that the regression formula established with the $\mathrm{DMOE}_{\mathrm{u}}$ as the independent variable had a higher explanatory power; this points to the same statistical trend as in the two above-mentioned sets of regression formulas for predicting the MOEstatic.

Relationship between the modulus of elasticity (MOE $\left.E_{\text {static }}\right)$ and the modulus of elasticity of the continuous mechanical stress rating machine (MOE $\left.E_{C M S R}\right)$

The relationships of the MOE static $_{\text {and MOE }}$ MSR are shown in Figs. 8 and 9. From the slope of linear regression shown in Fig. 8, it can be seen that the average MOE CMSR value and the central location of the specimen at $900 \mathrm{~mm}$ (as shown in Fig. 9) were both positively correlated to the $\mathrm{MOE}_{\text {static }}$ value. Additionally, the p-values of both sets of regression equations were found to be than 0.01 , which indicated that the regression equations were significant and had predictive value. The resulting positive correlation aligns with the research of Kretschmann and Hernandez (2006), who achieved the same correlational outcomes via MSR for Pinus ponderosa timber. The $\mathrm{R}^{2}$ value reached 0.98 , which indicated an exceptional predictive ability and the CMSR grading achieved high accuracy as a method for predicting the profile of the static bending elastic modulus. By comparing the $\mathrm{R}^{2}$ values in Figs. 4 and 5 with the $\mathrm{R}^{2}$ values in Figs. 8 and 9, it can be seen that using the MOECMSR as an independent variable to predict the regression of the MOEstatic gave a higher explanatory power. In particular, the MOECMSR in the middle of the specimen had a high explanatory power, which assists with deducing its relationship with the static bending modulus. Among the three detection methods, the detection method using CMSR achieved the highest correlation.

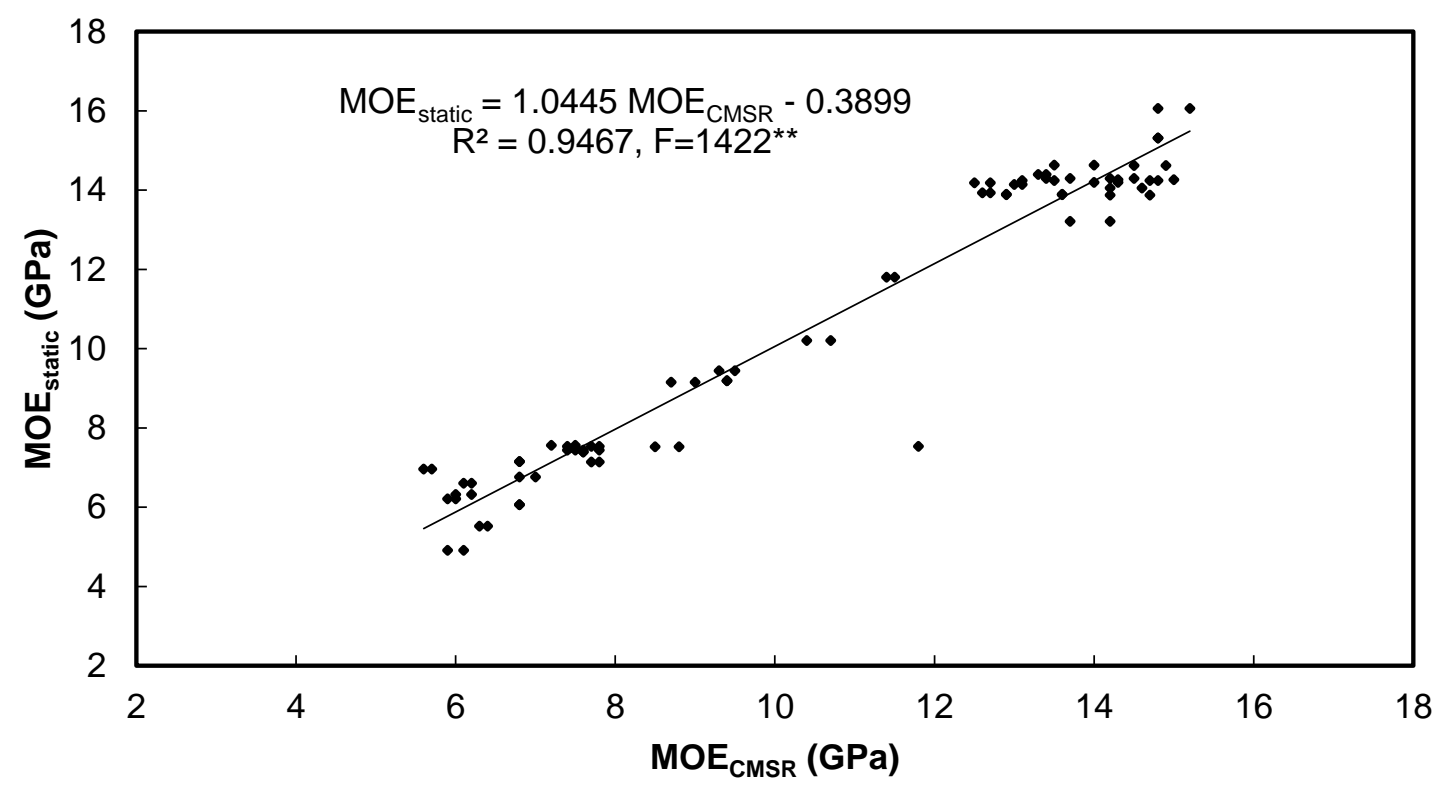

Fig. 8. Correlation between the MOE $\mathrm{CMSR}_{\mathrm{C}}$ and $\mathrm{MOE}_{\text {static }}$ of $C$. lanceolata 


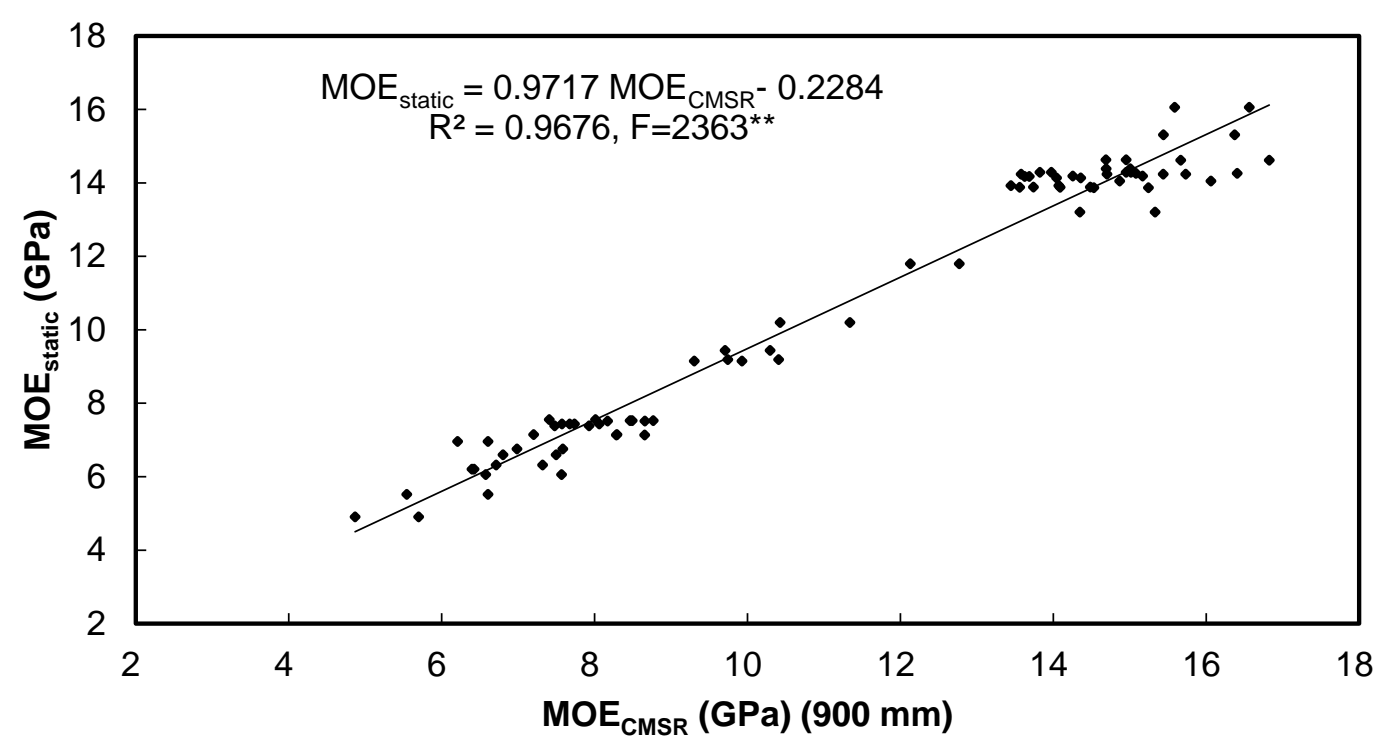

Fig. 9. Correlation between the $\mathrm{MOE}_{\mathrm{CMSR}}$ at the middle position $(900 \mathrm{~mm})$ and $\mathrm{MOE}_{\text {static }}$ of $C$. lanceolata

\section{The Grading Characteristics of Continuous Mechanical Stress Rating Equipment (CMSR)}

Difference between the feeding orientation and feeding method

In general, the bending strength is better when the bark side of the timber is extended. Therefore, when a timber sample has the bark side facing up, the lower grain angle achieves higher lamina strength (Olsson et al. 2013; Anderson et al. 2020). The CMSR equipment used in this research operates by bending the specimens upwards to obtain the MOE value. Therefore, the authors evaluated both side orientations in order to further understand the different impacts of both the feeding orientation and feeding method on CMSR analysis.

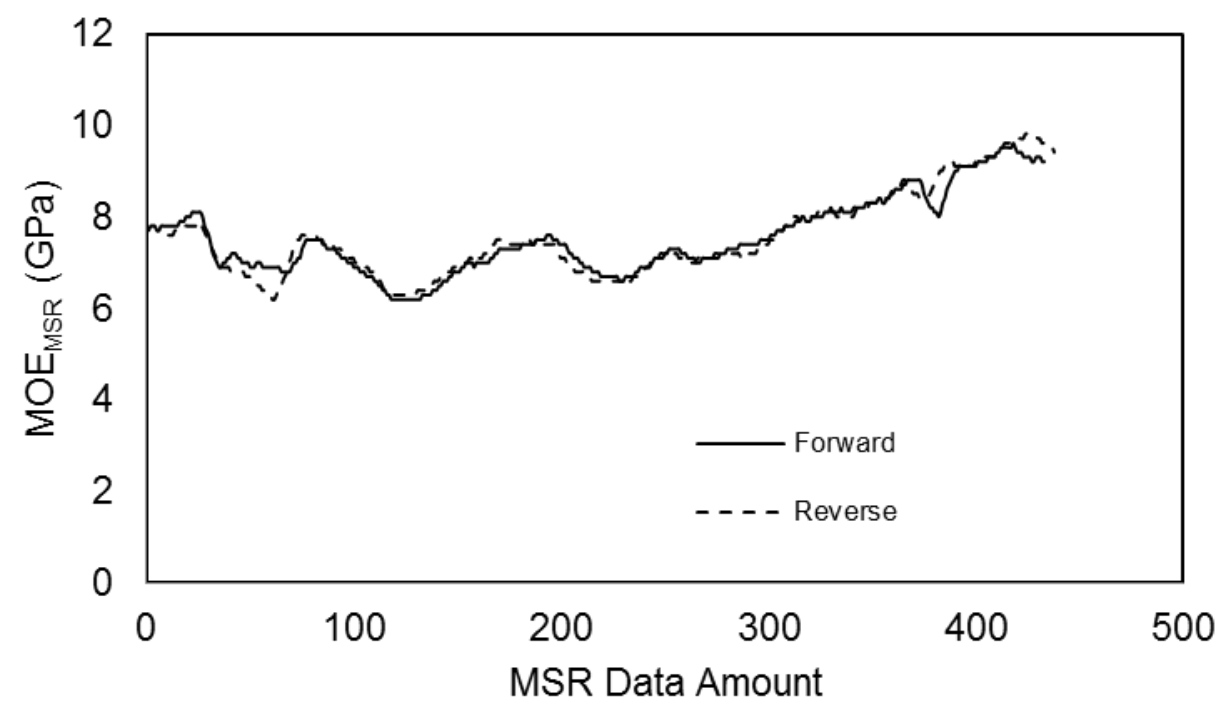

Fig. 10. Curve data of the forward and reverse MOE $E_{\text {cmsR }}$ progress of the $C$. lanceolata 
Table 4. Correlation Between the Direction of Bark Side and the Modulus of Elasticity of the Continuous Mechanical Stress Rating Machine (MOE $\mathrm{CMSR}_{\mathrm{S}}$ ) of $C$. lanceolata

\begin{tabular}{|c|c|c|c|c|c|c|c|c|c|}
\hline \multirow{3}{*}{$\begin{array}{l}\text { Grade } \\
(n)\end{array}$} & \multirow{3}{*}{$\mathrm{D}\left(\mathrm{kg} / \mathrm{m}^{3}\right)$} & \multirow{3}{*}{$V(\mathrm{~m} / \mathrm{s})$} & \multirow{3}{*}{$\begin{array}{l}\mathrm{DMOE}_{u} \\
(\mathrm{GPa})\end{array}$} & \multirow{3}{*}{$\begin{array}{c}\mathrm{MOE}_{\text {static }} \\
(\mathrm{GPa})\end{array}$} & \multicolumn{4}{|c|}{$\mathrm{MOE}_{\mathrm{CMSR}}(\mathrm{GPa})$} & \multirow{3}{*}{$\begin{array}{l}\text { Percentage Difference } \\
\text { Between the MOE } E_{C M S R} \text { in } \\
\text { Both Sides (\%) }\end{array}$} \\
\hline & & & & & \multicolumn{2}{|c|}{ Bark side up } & \multicolumn{2}{|c|}{ Bark side down } & \\
\hline & & & & & Average* & $900 \mathrm{~mm}^{* *}$ & Average* $^{*}$ & $900 \mathrm{~mm}^{* *}$ & \\
\hline $\begin{array}{l}\text { M30 } \\
(3)\end{array}$ & $393(6.7)^{a}$ & $4249(3.6)^{\mathrm{a}}$ & $7.1 \underset{a}{(11.9)}$ & $6.0(17.2)^{\mathrm{a}}$ & $5.9(4.5)^{\mathrm{a}}$ & $6.2(7.7)^{\mathrm{a}}$ & $5.8(2.0)^{a}$ & $5.8(14.3)^{a}$ & $-1.0 \pm 4.16^{\mathrm{a}}$ \\
\hline $\begin{array}{l}\text { M60 } \\
(14)\end{array}$ & $393(9.1)^{a}$ & $4533(6.4)^{\mathrm{a}}$ & $8.1 \underset{a}{(10.3)}$ & $7.1(12.1)^{a}$ & $7.3(12.1)^{b}$ & $7.9(10.6)^{a}$ & $7.3(11.1)^{\mathrm{a}}$ & $7.6(12.7)^{b}$ & $-1.8 \pm 7.68^{a}$ \\
\hline $\begin{array}{l}\text { M90 } \\
(4)\end{array}$ & $401(6.0)^{a}$ & $5176(4.2)^{b}$ & $10.7_{b}(8.8)$ & $10.2(11.6)^{b}$ & $10.3(9.8)^{c}$ & $11.2(10.2)^{b}$ & $10.1(9.7)^{b}$ & $10.5(10.8)^{c}$ & $-0.1 \pm 1.85^{a}$ \\
\hline $\begin{array}{c}\text { M120 } \\
(19)\end{array}$ & $465(4.2)^{\mathrm{b}}$ & $5640(2.7)^{\mathrm{c}}$ & $\begin{array}{c}14.8(7.9) \\
c\end{array}$ & $14.3(4.1)^{\mathrm{c}}$ & $14.0(5.0)^{d}$ & $14.8(7.1)^{\mathrm{c}}$ & $13.8(6.2)^{\mathrm{c}}$ & $14.9(5.1)^{d}$ & $0.8 \pm 3.13^{a}$ \\
\hline
\end{tabular}

Table 5. Difference Ratio in the Modulus of Elasticity of the Continuous Mechanical Stress Rating Machine (MOECMSR) Compared to Feeding Speed of $40 \mathrm{~m} / \mathrm{min}$

\begin{tabular}{|c|c|c|c|c|}
\hline \multirow{2}{*}{ Grade } & \multicolumn{2}{|c|}{$60 \mathrm{~m} / \mathrm{min}$} & \multicolumn{2}{c|}{$80 \mathrm{~m} / \mathrm{min}$} \\
\cline { 2 - 5 } & Bark side up & Bark side down & $-2.85 \pm 2.93$ & Bark side down \\
\hline M30 & $-0.12 \pm 5.00$ & $-2.41 \pm 5.10$ & $-2.88 \pm 2.18$ \\
\hline M60 & $-0.37 \pm 3.63$ & $0.36 \pm 6.67$ & $-2.42 \pm 2.11$ & $-0.41 \pm 3.98$ \\
\hline M90 & $-0.81 \pm 3.51$ & $-0.53 \pm 3.30$ & $-1.43 \pm 1.76$ & $-1.16 \pm 1.91$ \\
\hline M120 & $0.08 \pm 3.23$ & $-0.10 \pm 5.26$ & & $-1.46 \pm 2.67$ \\
\hline
\end{tabular}



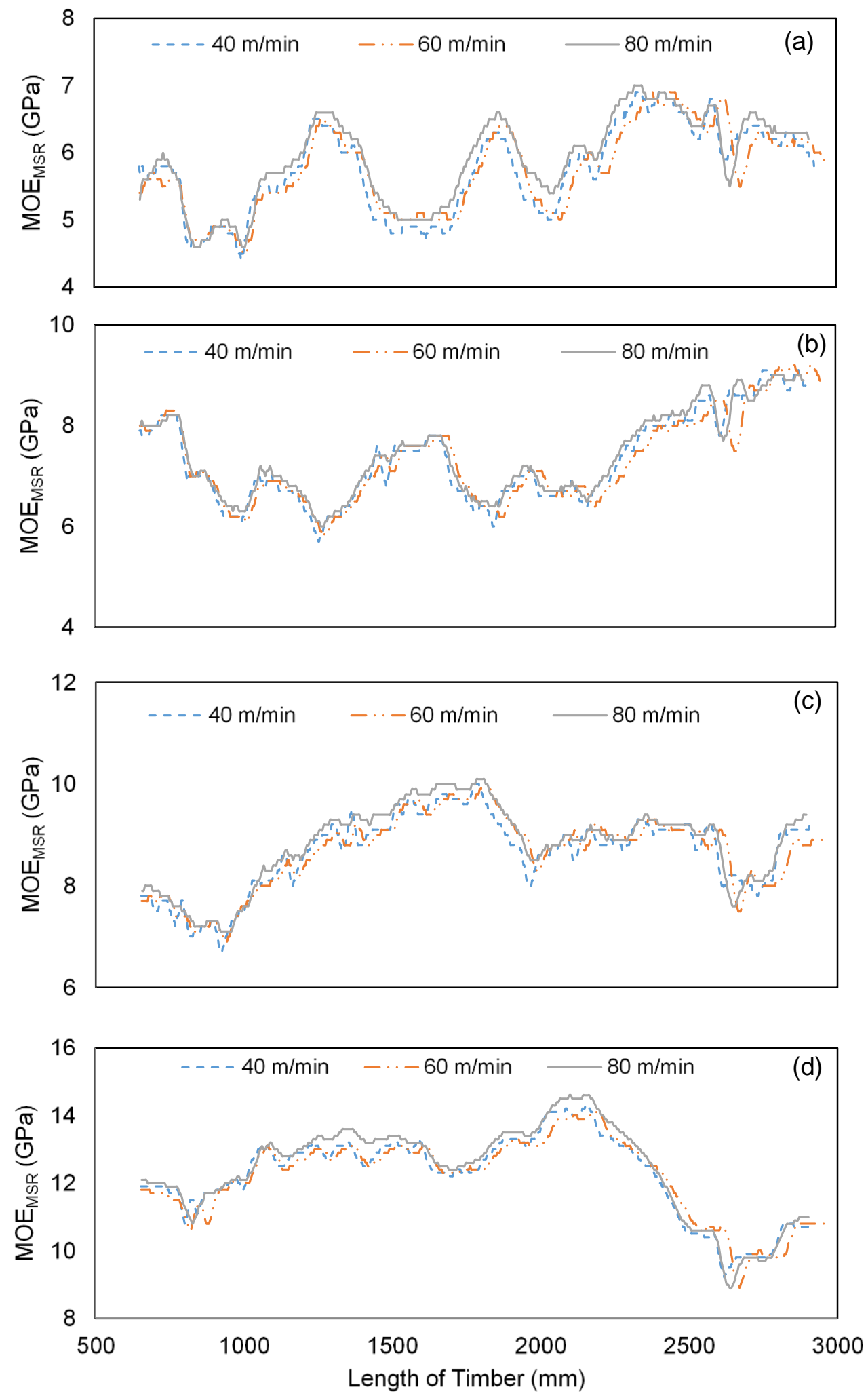

Fig. 11. Results of the MOE $E_{C M S R}$ in $M 30$ (a); M60 (b); M90 (c); and M120 (d) with different feeding speeds 
As shown in Table 4, the average difference in the lateral direction of the bark side of each grading was $1.8 \%$. However, the maximum standard deviation was $7.68 \%$, which indicated that there was no significant difference in the side orientation of the bark. However, it is still better to proceed with the bark side down when conducting CMSR testing. In addition, in order to evaluate whether the feeding direction of the specimens

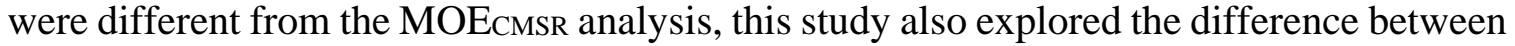
the curve data of the forward and reverse progress of the specimen. Figure 10 shows that the data of the forward or reverse progress had similar analysis results. It can be seen that the MOE feeding directions of the specimen did not affect the analysis results.

\section{Analytical characteristics of the continuous mechanical stress rating equipment (CMSR)} with different feeding rates

In this test, laminae of different strength levels were tested at speeds of 40,60 , and $80 \mathrm{~m} / \mathrm{min}$. The MOE ${ }_{\text {CMSR }}$ at the same position was calculated from the test distance of each

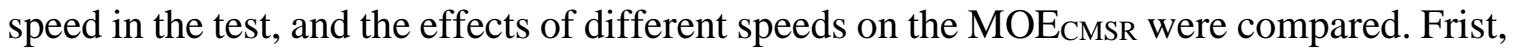
taking $40 \mathrm{~m} / \mathrm{min}$ as the test standard, the difference ratios of the MOECMSR obtained with different feeding speeds were calculated. Table 5 shows that as the feeding speed increased, the difference ratio of the MOE ${ }_{C M S R}$ of different grades of lamina trended downwards. From this result, it can be seen that increasing the feeding speed increased the MOECMSR detection difference. As shown in Fig.11a through 11d, it can be seen that the MOECMSR detection value at a feeding speed of $80 \mathrm{~m} / \mathrm{min}$ was higher than the MOECMSR detection value of the other two feeding speeds during the rating process.

However, feeding speeds of 40 and $60 \mathrm{~m} / \mathrm{min}$ produced alternating MOECMSR values. Although the $80 \mathrm{~m} / \mathrm{min}$ feeding speed was the fastest of all three, the results of all three feeding speeds showed no significant difference. Samson (1987) derived the

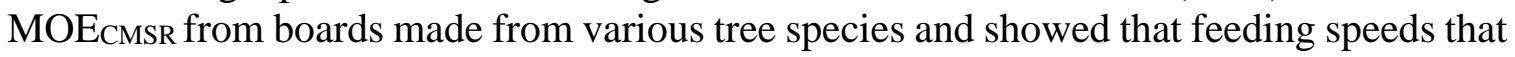
fall within the range of 0 to $350 \mathrm{~m} / \mathrm{min}$ did not lead to significant differences in the MOE values. This shows that the feeding speed has no significant effect on the MOE test results, which matches the trend shown in the results of this study. Therefore, based on the accuracy of the strength analysis and the consideration of grading efficiency, the authors recommend using $80 \mathrm{~m} / \mathrm{min}$ as the primary production speed to obtain more accurate MOECMSR measurements.

\section{Analyzed characteristics of difference break areas}

When the break area (BA) was decreased by $13 \%, 27 \%$, and $40 \%$, the effects of the various reductions in the BA on the MOECMSR are shown in Table 6. The cross-sectional area was reduced by $13 \%$ when a hole was drilled to a diameter of $12 \mathrm{~mm}$. As a result, the MOE was drilled to $36 \mathrm{~mm}$, the cross-sectional area was reduced by $40 \%$, and the MOECMSR was reduced to between $8.45 \%$ and $9.46 \%$. This result showed that the rate of decrease of the MOE lamina made from hard wood. The results showed that the MOE increased due to the increased thickness of the test material. The results of the bending test on different sized boards conducted by McNatt (1984) shows that as the size of the board decreased, the MOE coefficient of variation of the specimen tended to increase, i.e., the uniformity of the bending properties of the specimen were affected by the reduction in dimensions. Therefore, to ensure the accuracy and uniformity of the detection value of the MOECMSR, 
it is necessary to prevent the specimen from losing too much cross-sectional area ratio during and before the preparation process. Otherwise, it is necessary to produce a sufficient cross-sectional area size prior to preparation.

Table 6. Effect of Reduction in Break Area on the Modulus of Elasticity of the Continuous Mechanical Stress Rating Machine (MOEcmsR) Decrease Ratio

\begin{tabular}{|c|c|c|c|}
\hline $\begin{array}{c}\text { Reduction Rate } \\
\text { of BA }\end{array}$ & $\begin{array}{c}\text { Measuring Point MOE } \\
\text { (GPa) }\end{array}$ & $\begin{array}{c}\text { Decline Rate of Measuring } \\
\text { Point MOE (\%) }\end{array}$ & $\begin{array}{c}\text { Average MOE } \\
(\mathrm{GPa})\end{array}$ \\
\hline BA-0\% & 12.2 & - & 10.89 \\
\hline BA-13\% & 11.8 & 3.27 & 10.75 \\
\hline BA-27\% & 11.6 & 4.91 & 10.67 \\
\hline BA-40\% & 11.3 & 7.37 & 10.61 \\
\hline
\end{tabular}

\section{CONCLUSIONS}

1. The test results showed that the MOE static $_{\text {was }}$ positively correlated with the MOECMSR, $V_{\mathrm{u}}$, and DMOEu. Among them, the correlation between the $\mathrm{MOE}_{\text {static }}$ and $\mathrm{DMOE}_{\mathrm{U}}$ was higher than the correlation with the $V_{\mathrm{u}}$. The $\mathrm{R}^{2}$ values showed that the MOECMSR was more suitable as a detection method for predicting the $\mathrm{MOE}_{\text {static }}$ than other methods, e.g., the $V_{\mathrm{u}}$ or $\mathrm{DMOE}_{\mathrm{u}}$.

2. Results of the feeding orientation of the boards and whether the bark side direction was up or down did not have a significant influence on predicting the MOE value. Although the data from the forward and reverse feed directions were offset, the overlapped data had a high degree of repetition, which indicated that the feeding direction did not affect the detection results.

3. The feeding speed will affect the measured distance and the number of records, but there was no significant difference between the average MOE values obtained from the three feeding speeds.

4. To ensure the accuracy and uniformity of the MOECMSR detection value, it is necessary to avoid an excessively high break area ratio in the experimental material during the preparation process or to reserve enough break area size before preparation.

\section{ACKNOWLEDGEMENTS}

This study was supported by Grant No. 110-B01 from the Experimental Forest, College of Bioresource and Agriculture, National Taiwan University, Taiwan, ROC.

\section{REFERENCES CITED}

Anderson, G. C., Owens, F. C., Franca, F., Ross, R. J., and Shmulsky, R. (2020).

"Correlations between grain angle meter readings and bending properties of mill-run southern pine lumber," Forest Products Journal 70(3), 275-278. DOI: 10.13073/FPJ- 
D-20-00007

Brashaw, B. K., Bucur, V., Divos, F., Gonçalves, R., Lu, J., Meder, R., Pellerin, R. F., Potter, S., Ross, R. J., Wang, X., et al. (2009). "Nondestructive testing and evaluation of wood: A worldwide research update," Forest Products Journal 59(3), 7-14.

Cao, Y., Street, J., Li, M., and Lim, H. (2019). "Evaluation of the effect of knots on rolling shear strength of cross laminated timber (CLT)," Construction and Building Materials 222, 579-587. DOI: 10.1016/j.conbuildmat.2019.06.165

Chen, R., Wei, P. and Liu, J. (2005). "Utilization of compressed Chinese fir thinning wood," Chinese Journal of Applied Ecology 16(12), 2306-2310.

Chung, M. J., and Wang, S. Y. (2018). "Effects of peeling and steam-heating treatment on mechanical properties and dimensional stability of oriented Phyllostachys makinoi and Phyllostachys pubescens scrimber boards," Journal of Wood Science 64, 625-634. DOI: 10.1007/s10086-018-1731-y

CNS 2215 (2017). "Particleboards," Chinese National Standard, Bureau of Standards, Metrology and Inspection, Ministry of Economic Affairs (MOEA), Taipei, Taiwan.

CNS 11031 (2014). "Structural glued-laminated timber," Chinese National Standard, Bureau of Standards, Metrology and Inspection, Ministry of Economic Affairs (MOEA), Taipei, Taiwan.

Firmanti, A., Bachtiar, E. T. Surjokusumo, S., Komatsu, K., and Kawai, S. (2005). "Mechanical stress grading of tropical timbers without regard to species," Journal of Wood Science 51, 339-347. DOI: 10.1007/s10086-004-0661-z

França, F. J. N., Shmulsky, R., Ratcliff, T., Farber, B., Senalik, C. A., Robert, J., Ross, B., and Seale, R. D. (2021). "Interrelationships of specific gravity, stiffness, and strength of yellow pine across five decades," BioResources 16, 3815-3826. DOI: 10.15376/biores.16.2.3815-3826

Gaff, M., Babiak, M., Vokatý, V., Gašparík, M., and Ruman, D. (2017). “Bendability characteristics of hardwood lamellae in elastic region," Composites Part B: Engineering 116, 61-75. DOI: 10.1016/j.compositesb.2016.12.058

Ilic, J. (2001). "Relationship among the dynamic and static elastic properties of air-dry Eucalyptus delegatensis R. Baker," Holz als Roh- und Werkstoff 59, 169-175. DOI: $10.1007 / \mathrm{s} 001070100198$

JAS 1152 (2007). “Structural laminated timber,” Japanese Agricultural Standard Ministry of Agriculture, Forestry and Fisheries, Japan.

Kretschmann, D. E., and Hernandez, R. (2006). "Grading timber and glued structural members," in: Primary Wood Processing: Principles and Practice, J. C. F. Walker (ed.), Springer, Dordrecht, Netherlands, pp. 339-390.

Kovryga, A., Schlotzhauer, P., Stapel, P., Militz H., and Kuilen, J. Wi. G. (2019). "Visual and machine strength grading of European ash and maple for glulam application," Holzforschung 73, 773-787. DOI: 10.1515/hf-2018-0142

Kovryga, A., Chuquin Gamarra, J. O., and Kuilen, J. W. G. (2020). "Strength and stiffness predictions with focus on different acoustic measurement methods," European Journal of Wood and Wood Products 78, 941-949. DOI: 10.1007/s00107020-01584-Z

Lee, C. J., Chang, T. C., and Chung, M. J. (2021). "Effects of gluing conditions for formaldehyde-free tannin adhesive on the oriented bamboo scrimber board properties," European Journal of Wood and Wood Products 79, 1623-1631. DOI: 0.1007/s00107-021-01701-6

McEwan, A., Enrico, M., Raffaele, S., and Michal, B. (2020). "Past, present and future of 
industrial plantation forestry and implication on future timber harvesting technology," Journal of Forestry Research 31, 339-351. DOI: 10.1007/s11676-019-01019-3

McNatt, J. D. (1984). "Static bending properties of structural wood-base panels: Largepanel versus small-specimen tests," Forest Products Journal 34(4), 50-54.

Olsson, A., Oscarsson J., Serrano, E., Källsner, B., Johansson, M., and Enquist, B. (2013). "Prediction of timber bending strength and in-member cross-sectional stiffness variation on the basis of local wood fibre orientation," European Journal of Wood and Wood Products 71, 319-333 DOI: 10.1007/s00107-013-0684-5

Pirard, R., Secco, L. D., and Warman, R. (2016). "Do timber plantations contribute to forest conservation?," Environmental Science \& Policy 57, 122-130. DOI: 10.1016/j.envsci.2015.12.010

Ross, R. J. (2015). Nondestructive Evaluation of Wood: Second Edition (FPL-GTR-238), U.S. Department of Agriculture Forest Products Laboratory, Madison, WI.

Samson, M. (1987). "Effect of speed on the accuracy of stress-grading machines for lumber," Wood Science and Technology 21(3), 281-292.

Wang, S.-Y., Chen, J.-H., Tsai, M.-J., Lin, C.-J., and Yang, T.-H. (2008). "Grading of softwood lumber using non-destructive techniques," Journal of Materials Processing Technology 208(1-3), 149-158. DOI: 10.1016/j.jmatprotec.2007.12.105

Article submitted: September 21, 2021; Peer review completed: November 30, 2021;

Revised version received and accepted: December 20, 2021; Published: January 10, 2022. DOI: 10.15376/biores.17.1.1411-1426 